\title{
Factors Determining the Adoption of Energy-Saving Technologies in Swiss Firms: An Analysis Based on Micro Data
}

Journal Article

Author(s):

Arvanitis, Spyros; Ley, Marius

Publication date:

2013-03

Permanent link:

https://doi.org/10.3929/ethz-a-010016465

Rights / license:

In Copyright - Non-Commercial Use Permitted

Originally published in:

Environmental and Resource Economics 54(3), https://doi.org/10.1007/s10640-012-9599-6 


\title{
Factors Determining the Adoption of Energy-Saving Technologies in Swiss Firms: An Analysis Based on Micro Data
}

\author{
Spyros Arvanitis • Marius Ley
}

Accepted: 30 August 2012 / Published online: 16 September 2012

(C) Springer Science+Business Media B.V. 2012

\begin{abstract}
This study investigates the factors that determine firms' decisions to adopt energysaving technologies. We distinguish between the decisions of whether or not to use a technology ("inter-firm diffusion"), and of how intensely to use a technology ("intra-firm diffusion"). The empirical model used accommodates several effects that have been postulated in the theoretical diffusion literature: firm and industry heterogeneity, strategic considerations and external effects. Data for 2,324 Swiss firms for the year 2008 is used, with separate information for four categories of energy-saving technology applications (electromechanical and electronic, motor vehicles and traffic engineering, construction, power-generating processes). The results reveal significant differences with respect to firm characteristics and adoption barriers between inter-firm and intrafirm diffusion. In practically all cases, positive net external effects of adoption can be found. Inducement effects, particularly those traced back to intrinsic motivations for environment-friendly technologies, show clearly positive effects on adoption behavior.
\end{abstract}

Keywords Energy efficient technologies · Energy-saving technologies ·

Technology adoption $\cdot$ Technology diffusion

\section{Introduction}

Energy efficiency and energy policy have been on the top of the agenda of economic research in recent years. Moving towards an economy that uses energy in a more sustainable manner

Electronic supplementary material The online version of this article (doi:10.1007/s10640-012-9599-6) contains supplementary material, which is available to authorized users.

This study was financed by the Swiss Federal Office of Energy (SFOE).

S. Arvanitis · M. Ley $(\varangle)$

KOF Swiss Economic Institute, ETH Zurich, 8092 Zurich, Switzerland

e-mail: ley@kof.ethz.ch

S. Arvanitis

e-mail: arvanitis@kof.ethz.ch 
will remain a major challenge to enterprises and policymakers for the near future and beyond, despite the obvious difficulties encountered by international politics to agree on binding reduction targets for greenhouse gas emissions. It is clear that the implementation of technologies and practices that increase firms' and households' energy efficiency — that is to say, which enable to produce or provide given amounts of goods or services using less energy inputs-are of crucial importance to meet this challenge. Only then can we expect to maintain the high level of standard of living industrialized countries enjoy today and developing countries are striving to catch up with.

Several academics (Popp et al. 2009 provide a survey) and practitioners (most prominently, McKinsey \& Company with their "Greenhouse gas abatement cost curves" initiative ${ }^{1}$ ) have pointed to the fact that adoption of energy-saving technologies among firms takes place slowly or not at all even in cases where the potential private gains (through lower energy input requirements or related cost savings) outweigh the associated costs. In a more longterm and macro-oriented setting, some narrative and empirical findings likewise suggest that increased involvement in green technology (or, specifically, energy efficiency) may have noticeable welfare-enhancing effects rather than causing net costs or a decrease of a country's competitiveness (see, for instance, Cadot et al. 2009 for a cross-country, cross-industry survey on the topic).

This paper thus attempts to shed light on the driving forces of the diffusion of readyto-use energy efficient technologies among firms. Much of the existing literature on new technology (and, specifically, green technology) solely focuses on the R\&D and innovation stage, rather than the actual dissemination of such technology among final users. This seems odd, given the observed fact that "the diffusion of a technology is a very slow and heterogeneous process and this is true (...) for green technologies that are notoriously slower than traditional technologies at diffusing within and across firms" (Battisti 2008, p. 29). Notable exceptions to this perceived lack of diffusion studies in the field of energy conservation are presented in Sect. 2. ${ }^{2}$ However, the concern remains that, largely due to data restrictions, empirical research so far has focused primarily on the patterns of inter-firm diffusion (that is, the analysis of which firms are technology users, no matter to what degree they actually use a technology) and neglected intra-firm diffusion (the extent to which the new technology is used among technology users); see again Battisti (2008).

Some more relevant questions that remain open have been listed by Montalvo (2008) in the context of a broad survey of studies dealing with the subject, namely the multitude of factors potentially affecting the adoption decision at the firm level and the limited availability of longitudinal data, which severely restricts the possibility to investigate the dynamics of diffusion processes. In addition, findings of industry-specific surveys often cannot be generalized to the whole economy and for some time research of technology diffusion has been divided in different streams that are difficult to reconcile with each other.

A further branch of literature focuses on the slowness of the dissemination of technologies that enhance energy efficiency and analyzes the reasons for the "energy-efficiency gap" that presumably exists between actual and optimal level of energy efficiency (see, e.g., Jaffe and Stavins 1994 and DeCanio 1993). As a consequence, some empirical papers concentrate on the potential barriers of the diffusion of energy-saving technologies, thus neglecting other

\footnotetext{
1 http://www.mckinsey.com/clientservice/ccsi/costcurves.asp.

2 However, the fact that The Journal of Cleaner Production dedicated in 2008 a special issue to the diffusion of cleaner technologies (Volume 16, Issue 1, Supplement 1, pp. S1-S184) shows that there is an increasing interest for this subject.
} 
important factors that may impact the adoption rate (see, e.g., De Groot et al. 2001; DeCanio 1998; and Reddy and Painuly 2004).

We attempt to overcome some of these difficulties by drawing on a new dataset of Swiss firms that has been collected by means of a survey specifically designed to this task, covering a broad range of particular energy efficient technologies as well as stemming from a wide spectrum of enterprises covering the industrial (including energy and water) as well as the construction and service sectors. We are capable of implementing an econometric approach that allows some inference about market and non-market intermediated externalities as well as differentiating between the inter-firm and intra-firm aspects of technology diffusion.

The paper is structured as follows. Section 2 reviews empirical studies of adoption of energy-saving technologies. In Sect. 3 the theoretical background and the model specification are presented. Section 4 describes the data used in this study and contains descriptive information about the inter-firm and intra-firm adoption rates of energy-saving technology applications. In Sect. 5 the empirical results are presented and discussed. Section 6 contains a summary and some conclusions.

\section{Empirical Studies of Adoption of Energy-Saving Technologies}

There are relatively few empirical studies dealing with the diffusion of energy-saving technologies at the firm level. Many of these studies do not use the theoretical background of this study (and of other similar studies; see Sect. 3) but concentrate on the investigation of barriers of diffusion of energy-saving technologies. We discuss here five of them that use firm data for more than one industry.

In a study based on data for 285 larger US companies in three energy-intensive industries (plastics; petroleum; and steel) Pizer et al. (2002) investigated the determinants of the adoption of energy-saving technologies in the period 1991-1994. The factors that were found to enhance the adoption rate were firm size, profits and- to a smaller extent-energy prices.

De Groot et al. (2001) found in a study for 135 Dutch firms for the year 1998 positive effects of the energy intensity and the investment ratio (total investments as a fraction of sales) on the adoption rate in the horticulture industry, a positive effect of the investment ratio but mixed positive and negative effects of competitive pressures in the horticulture, the metal industry and the (pooled) group of industries consisting of machinery, textiles and construction materials industry. Rather astonishingly, a positive firm size effect could be found only for the industry for basic metals. The most important barriers have been quite heterogeneous among industries: lack of compatibility with existing technologies (industry for basic metals; horticulture industry); organizational problems (horticulture industry); lack of internal financing (sub-sector of machinery, textiles and construction materials industry); lack of public subsidies (paper industry); and no need for further increase of energy efficiency (basic metals and food industry).

In a further study for 110 Dutch firms Velthuijsen (1993) found that the following factors have been significant reasons for not implementing energy efficiency improvement opportunities: limited financial means; lack of information; no need to renew existing equipment; and lack of interest due to the fact that energy-saving does not belong to firms' core business.

Using a sample of more than 300 Dutch firms, Gillissen and Opschoor (1995) empirically identified variables explaining investment behavior with regards to energy conservation. They found that such investment decisions were largely based on the outcome of the respective firms' economic evaluation, taking into account physical and financial constraints. The main determinants they identified were firm size, return on investment, availability of capital 
and the rate of depreciation; whereas barriers that prevailed were uncertainty as to expected energy prices, budgetary problems, poor financial market expectations and lack of knowledge about energy conservation technologies as well as their perceived complexity.

A study based on data for 50 Greek firms in 2004/2005 found that primarily the metal industry out of six industries suffered under a series of impediments such as lack of fund; high investment costs; high transaction costs; managerial deficiencies and uncertainty with respect to the development of energy prices (Sardianou 2008).

\section{Framework of Analysis}

\subsection{Theoretical Background}

In a recent paper Battisti et al. (2009) presented a model of diffusion that integrates the analysis of inter-firm and intra-firm diffusion, which have mostly been modeled separately until now, into an encompassing framework. ${ }^{3}$ Their study is an extension of Karshenas and Stoneman (1993) and subsequent work of Battisti (2000) and constitutes the main base for our conceptual framework. The core assumption is that firms choose the extent to which they use a technology in order to maximize their expected profits, given their own characteristics as well as a number of factors that characterize the market (or the industry), in which they operate. Such a framework allows for a clearer focus on the following questions:

(i) What determines whether firms adopt a certain technology (inter-firm diffusion), and what determines how intensely they use this technology (intra-firm diffusion)?

(ii) To what extent are individual firms influenced by the behavior of other similar firms in their decision to adopt a certain technology (external experience effects)?

In formal terms, we express the expected profit $E\left[\Pi_{i}(t)\right]$ from the use of a first unit of a new technology (if non-user) or the extension of use (if already a user) by one unit as a function of the following factors: $x_{i}(t)$ the extent of technology adoption chosen by firm $i$ in period $t$; firm characteristics $F_{i}(t)$; industry characteristics $F_{j}(t)$; stock and order effects $S O_{j}(t)$; learning and network effects $E_{i}(t)$ and $E_{j}(t)$ [so-called "epidemic" effects, where we differentiate between within-firm effects $E_{i}(t)$ and industry-wide effects $E_{j}(t)$ ]; and inducement effects $I A(t)$ that reflect potential encouragement by public policy to adopt a certain technology, both by pecuniary and non-pecuniary means. ${ }^{4}$ A profit-maximising firm under conditions of perfect competition would choose $x_{i}(t)^{*}$ such that the expected (marginal) profit $E\left[\Pi_{i}(t)\right]$ equals the price of (a unit of) technology use $P_{i}(t)$ :

$$
E\left[\Pi_{i}(t)\right] \equiv \Pi_{i}\left[x_{i}(t)^{*}, F_{i}(t), F_{j}(t), S O_{j}(t), E_{i}(t), E_{j}(t), I A(t)\right]=P_{i}(t)
$$

(firm $i$; industry $j$ )

It can be shown that:

$$
x_{i}(t)^{*}=G\left[F_{i}(t), F_{j}(t), S O_{j}(t), E_{i}(t), E_{j}(t), P_{i}(t), I A(t)\right]
$$

The constituents of this equation deserve some more explanation, in order to put them into the context of existing theoretical and empirical diffusion literature:

\footnotetext{
${ }^{3}$ For recent reviews of the literature on the theory of technology diffusion in general see Sarkar (1998) and Geroski (2000).

4 The original model in Battisti et al. (2009) does not include a variable for inducement effects. We expanded the model to take into account also this important factor.
} 
(1) Characteristics of a firm $i$ (a vector $F_{i}(t)$ of variables that have to be specified) and its environment (a vector $F_{j}(t)$ of variables for industry $\mathrm{j}$ that have also to be specified) reflect rank effects. Rank effects refer to heterogeneity across different firms that could lead to differing returns to adoption and thus differing reservation prices (see, e.g., Davies 1979 and Ireland and Stoneman 1986). In the present context, the interfirm concept of rank effects is extended to intra-firm technology use. These effects are expected in general to be positive.

(2) The extent of industry usage of new technology $S O_{j}(t)$ captures inter-firm stock and order effects (i.e., market-intermediated externalities). ${ }^{5}$ Stock effects are based on the assumption that the returns to technology adoption decrease with the number of other firms utilizing this technology (see, e.g., Reinganum 1981). At a given point in time, it is thus optimal only for a certain fraction of firms to be adopters of the technology in question. If adoption costs fall over time (as is usually assumed in models featuring stock effects), a time path is mapped out for adoption, along which technology use gradually increases over time.

Similarly, order effects assume that other firms' adoption behavior negatively affects the profitability of technology adoption. In contrast to stock effects, these negative effects are assumed to be due to first mover advantages. Thus, profit maximizing firms strategically decide upon technology adoption, taking into account other firm's behavior (and, potentially, their expectation about other firms' future adoption behavior). Consequently, not only the total number of technology adopters is crucial for a firm's expected profit gain, but also the order by which each firm has become (or is to become) a technology user, justifying the name "order effects".

In summary, both stock and order models posit that for a certain level of adoption costs at a certain point in time, it is profitable to be the first adopter; and as costs decrease with time, adoption becomes profitable also for a second firm, then a third, and so on (see, e.g., Fudenberg and Tirole 1985). By definition, these effects are negative, however on balance positive network effects (see below) may be strong enough to outweigh them.

(3) Positive epidemic effects (i.e., learning and network non-market intermediated externalities) reflect either the firm's own experience with the new technology $E_{i}(t)$, often proxied by the time since the firm's first adoption, or the experience gained from observing other firms $E_{j}(t)$ (often proxied by the extent of technology diffusion among similar firms in time $t$ ).

(4) The expected adoption cost of a unit technology $P_{i}(t)$ is constituted by two parts: one common to all firms, e.g., the price of machines; and a second one reflecting firm-specific adjustment and installation costs.

(5) In accordance to the particular conditions of the introduction of energy-saving technologies in Switzerland (as in many other countries), also elements of the literature on induced innovation and technology diffusion (see, e.g., Binswanger 1974) are taken into consideration. The diffusion of energy-saving technologies can be positively influenced (a) through increases of energy prices and/or taxes (see, e.g., Linn 2008 and Jacobs et al. 2009) and (b) through public regulation and/or public incentives to use energy-saving technologies (see, e.g., Popp et al. 2009). We consider a vector $I A_{i}(t)$ of variables that capture the influence of such factors (inducement effects). These variables are reflecting both firm-specific (e.g., due to high share of energy costs; due to value-oriented "in-

\footnotetext{
5 External effects intermediated by the market are so-called "pecuniary externalities" that arise from direct pecuniary benefits to users; external effects that are not intermediated by the market are so-called "technological externalities" and encompass indirect benefits through learning effects (see Battisti et al. 2009, p. 141 and further literature cited there).
} 
trinsic" effects) and industry-specific or economy-wide effects (e.g., due to high energy prices).

As expressed in Eq. (2), the adoption of new technology as well as the more intensive use of it constitute a dynamic process. However, since we dispose of data only for a single cross-section, it is not possible to specify a dynamic model. Instead, we apply a static version of the model to investigate the determinants of the diffusion of energy-saving technologies in the Swiss business sector in the year 2008. As a consequence, the variable $E_{i}(t)$ reflecting the firms' individual experience of the new technology cannot be measured in a single crosssection and has to be ignored. The finally operative expression of Eq. (2) after dropping the time subscripts is as follows:

$$
x_{i}=G\left[F_{i}, F_{j}, S O_{j}, E_{j}, P_{i}, I A\right]
$$

\subsection{Model Specification}

We specified an empirical model that contains the same determinants for both inter- and intra-firm diffusion. Table 1 describes the adoption variables (i.e., the dependent variables) used in this study. Table 2 gives an overview of the variables used as determinants of adoption.

Based on information of the International Energy Agency (see IEA 2008), we distinguished among four groups of energy-saving technology applications: (a) electromechanical and electronic applications (e.g., energy-saving in machines either by substitution for more energy efficient machines or by modification of already installed machines towards more energy efficiency); (b) applications specific to motor vehicles and traffic engineering; (c) applications in building construction; and (d) applications in power-generating processes. Each of these four main groups of energy-saving technology applications was further divided into more specific applications, e.g., we distinguish under the heading applications of type (d) between heat pumps, heat recuperation systems and combined heat-and-power generation based on biomass or gas/carbon.

Table 3 lists in detail the respective technology applications that constitute each of the four groups, alongside some descriptive statistics. We measure inter-firm diffusion by the binary variable "adoption of at least one energy-saving technology application in one of the technology fields defined in Table 3 up to 2008 (yes/no)" (see also Table 1). Intra-firm diffusion is measured by the number of technology applications of a certain technology field defined in Table 3 adopted by the firm up to 2008 (see also Table 1).

Distinguishing between these four groups of energy-saving technologies allows for a more differentiated analysis of the determinants of adoption than if we considered all applications as simply belonging to one large, uniform group. We should not rule out a priori the possibility that determinants differ in their effect and magnitude across various technology groups. To this end, we set up our estimation procedure in a way that lets the data indicate if determinants of adoption are heterogeneous across groups.

With four dependent variables (one for each technology group), implementing Eq. (2a) thus comes down to estimating a system of four simultaneous equations. Potential interdependencies within each firms' adoption decisions should then be taken into account by allowing unobserved disturbances to be correlated across the four technology groups. Neglecting such interdependencies could lead in the context of non-linear estimators to inconsistent parameter estimates, further, to the loss of valuable insights on technology complementarities. Technology complementarities between two technology groups arise if firms perceive the joint adoption of technologies belonging to both groups as providing an additional profit 
Table 1 Definition of the dependent variables

Variable Description (reference year: 2008)

Inter-firm diffusion

MACHINE

TRANSPORT

BUILDING

ENERGY

Intra-firm diffusion

MACHINE_N_0

TRANSPORT_N_0

BUILDING_N_0

ENERGY_N_0

MACHINE_N_5

TRANSPORT_N_3

BUILDING_N_5

ENERGY_N_4

Binary variable: 1: adoption of at least one out of five technology applications listed under (a) in Table 3; 0: otherwise

Binary variable: 1 : adoption of at least one out of three technology applications listed under (b) in Table 3; 0: otherwise

Binary variable: 1: adoption of at least one out of five technology applications listed under (c) in Table 3; 0: otherwise

Binary variable: 1 : adoption of at least one out of four technology applications listed under (d) in Table 3; 0: otherwise

3-level ordinate variable: level 2: adoption of 3, 4 or 5 of the technology applications listed under (a) in Table 3; level 1: adoption of 1 or 2 of the technology applications listed under (a); level 0: otherwise

3-level ordinate variable (level 2: adoption of 2 or 3 of the technology applications listed under (b) in Table 3; level 1: adoption of 1 of the technology applications listed under (b); level 0: otherwise

3-level ordinate variable (level 2: adoption of 3, 4 or 5 of the technology applications listed under (c) in Table 3; level 1: adoption of 1 or 2 of the technology applications listed under (a); level 0: otherwise

3-level ordinate variable (level 2: adoption of 2, 3 or 4 of the technology applications listed under (d) in Table 3; level 1: adoption of 1 of the technology applications listed under (d); level 0: otherwise

5-level ordinate variable: 1, 2, 3, 4, 5 of the technology applications listed under (a) in Table 3; reference level: 0

3-level ordinate variable: 1,2, 3 of the technology applications listed under (b) in Table 3; reference level: 0

5-level ordinate variable: 1, 2, 3, 4, 5 of the technology applications listed under (c) in Table 3; reference level: 0

4-level ordinate variable: 1, 2, 3, 4 of the technology applications listed under (d) in Table 3; reference level: 0

gain relative to the sum of gains that would result from the isolated adoption of each of these technologies. Such complementarities should then manifest themselves in the data in the form of positive correlation of adoption probabilities, once we condition on exogenous factors, which is precisely what the multivariate probit estimator to be used in the present study does. Likewise, the possibility that technology groups are perceived as substitutes to each other (i.e., the opposite case to complements) is accommodated by this estimation strategy: this case would be reflected by negative correlations of adoption probabilities, conditional on all exogenous variables.

Turning to the explanatory variables, we used the following variables to measure firmspecific rank effects $F_{i}$ :

Factor endowment. A firm's factor endowment, especially its endowment in human capital and know-how, is an important factor determining the firm's ability to adequately utilize new technologies. Capital intensity is measured by gross investment per employee (LOG_INVEST/EMPL), human capital intensity is measured by the share of employees with tertiary-level education (HQUAL), know-how intensity is measured by the ability to generate new knowledge as reflected in the existence of permanent R\&D activities (R\&D). We expect positive effects for all three variables. 
Table 2 Definition of the independent variables

Variable Description

Independent variables

Firm-specific rank effects

LOG_EMPL

LOG_INVEST/EMPL

INVEST/EMPL_0

HQUAL

R\&D

EXPORT

FOREIGN
Natural logarithm of the number of employees (in full-time equivalents) by the end of the year 2008

Natural logarithm of gross investment expenditure per employee (value null for firms with null gross investment) in the year 2008

Dummy variable for firms with null gross investment in the year 2008

Employment share of employees with tertiary-level education by the end of the year 2008

R\&D activities yes/no (dummy variable) in the period 2006-2008

Export activities yes/no in the year 2008

Foreign-owned firm yes/no (dummy variable)

Rank effects as to a firm's market environment

DEMAND_EXPECT

PRICE_COMP

NONPRICE_COMP

IND1-IND7

Epidemic effects

Inter-firm

INTER_MACHINE

INTER_TRANSPORT

INTER_BUILDING

INTER_ENERGY

Intra-firm

INTRA_MACHINE

INTRA_TRANSPORT

INTRA_BUILDING

INTRA_ENERGY

Adoption costs

Barriers of adoption

INFORMATIONAL

COMPATIBILITY
Expected change of demand for a firm' s main product for the period 2009-2011 (5-level ordinate variable based on a five-point intensity scale: values $1-5)$

Intensity of price competition (5-level ordinate variable based on a five-point intensity scale: values $1-5)$

Intensity of non-price competition (5-level ordinate variable based on a five-point intensity scale: values $1-5)$

Subsectors: IND1: NACE 22, 335, 36, 37; IND2: NACE 21, 23, 24, 25, 26, 27, 28, 40, 41; IND3: NACE 29, 31, 30, 31, 32, 331-334, 34, 35; IND4: NACE 45; IND5: 50, 51, 52; IND6: 55, 60-63, 70, 71; IND7: 64, 65-67, $72,73,74,93$; reference: NACE 15-20

Share of firms adopting at least one out of 5 technology applications listed under (a) in Table 1 by 2-digit industry

Share of firms adopting at least one out of 3 technology applications listed under (b) in Table 1 by 2-digit industry

Share of firms adopting at least one out of 5 technology applications listed under (c) in Table 1 by 2-digit industry

Share of firms adopting at least one out of 4 technology applications listed under (d) in Table 1 by 2-digit industry

Mean of adopted technology applications listed under (a) in Table 1 (only adopting firms) by 2-digit industry

Mean of adopted technology applications listed under (b) in Table 1 (only adopting firms) by 2-digit industry

Mean of adopted technology applications listed under (c) in Table 1 (only adopting firms) by 2-digit industry

Mean of adopted technology applications listed under (d) in Table 1 (only adopting firms) by 2-digit industry

Factor values; see Table A.4 in the Appendix (downloadable from the journal website, or available from the authors upon request)

Information and knowledge barriers: uncertainty with respect to technology performance, uncertainty about the future price development

Adjustment barriers: lack of compatibility with current product programme or current production technology 
Table 2 Continued

\begin{tabular}{|c|c|}
\hline Variable & Description \\
\hline FINANCIAL & Financing barriers: high investment expenditures, liquidity constraints \\
\hline ORGANIZATIONAL & $\begin{array}{l}\text { Organizational and managerial barriers: lack of know-how, of specialized } \\
\text { personnel, of management attention }\end{array}$ \\
\hline \multicolumn{2}{|l|}{ Inducement effects } \\
\hline LOG_EXP_ENERGY & $\begin{array}{l}\text { Natural logarithm of the sales share of energy costs (value null for firms } \\
\text { with null sales share) in the year } 2008\end{array}$ \\
\hline EXP_ENERGY_0 & Dummy variable for firms with null sales share \\
\hline ENV_AWARE & $\begin{array}{l}\text { Environmental criteria are taken into consideration for purchases of } \\
\text { intermediate inputs (5-level ordinate variable based on a five-point } \\
\text { intensity scale: values } 1-5)\end{array}$ \\
\hline Motives of adoption & $\begin{array}{l}\text { Factor values; see Table A.5 in the Appendix (downloadable from the } \\
\text { journal website, or available from the authors upon request) }\end{array}$ \\
\hline PRICE_TAX & Current and/or expected increases of energy prices and/or energy taxes \\
\hline PUBLIC_INCENT & Public incentives for energy efficiency and/or $\mathrm{CO}_{2}$ reduction \\
\hline PUBLIC_REGUL & $\begin{array}{l}\text { Public regulations and /or agreements between firms and government } \\
\text { agencies concerning energy efficiency }\end{array}$ \\
\hline OTHER & Demand for environment-friendly products; expected energy bottle-necks \\
\hline
\end{tabular}

Firm size. Here measured by the number of employees in full-time equivalents (LOG_EMPL), firm size may capture firm-specific characteristics relevant for the technology adoption that are not specified in this model, such as management abilities, scale economies, etc. This variable has been widely used as a determinant of technology diffusion in earlier studies; most of these studies have found, at least for the case of inter-firm diffusion, a positive effect of firm size (see, e.g., Karshenas and Stoneman 1995 for a survey of this literature). There is a further line of argumentation stating that due, for example, to managerial diseconomies of scale larger firms, once they have adopted a new technology, tend to use it less intensively than smaller ones; in this case a negative effect of firm size on intra-firm technology adoption is expected (see, e.g., Fuentelsaz et al. 2003).

Export activities. Here measured by a dummy variable (export activities yes/no; EXPORT) may indicate an above-average propensity to adopt new technology in order to keep high its international competitiveness. A positive effect on diffusion is expected.

Foreign-ownership. Here measured by a dummy variable (foreign-owned firm yes/no; FOREIGN) indicates whether a firm is controlled by a foreign parent company. We expect in general a higher than average propensity of foreign-owned firms to adopt new technologies. However, depending on the conditions in their home country, foreign-owned firms may react differently as domestic firms to public regulation and/or incentives with respect to energy-saving in the host country. As a consequence, the sign of this variable is not a priori clear.

To measure rank effects as to the firm's market environment $F_{j}$ we considered the following variables:

Demand prospects: Positive demand expectations (DEMAND) as perceived by the firms themselves may enhance the propensity to adopt new technologies because firms expect to distribute acquisition and adoption costs on a larger volume of products.

Competitive pressures: A well-known line of argumentation states that it is the elasticity of demand faced by a firm in its specific market that induces innovative or imitative activity (see Kamien and Schwartz 1970 for the original argument). In those markets where competition 
Table 3 Inter-firm diffusion of energy-saving technologies

\begin{tabular}{|c|c|c|}
\hline \multirow[t]{2}{*}{ Type of energy-saving technology application } & \multicolumn{2}{|c|}{ Number and share of adopters } \\
\hline & $N$ & $\%$ \\
\hline $\begin{array}{l}\text { (a) Energy-saving technologies in electromechanical } \\
\text { and electronic applications, namely* }\end{array}$ & 914 & 39.6 \\
\hline In electrical machines and drive systems & 567 & 24.6 \\
\hline In information and communication technologies & 554 & 24.0 \\
\hline In consumer electronics & 213 & 9.2 \\
\hline $\begin{array}{l}\text { In components of process engineering (e.g., } \\
\text { compressors; pumps; heat exchangers) }\end{array}$ & 577 & 25.0 \\
\hline In process engineering & 358 & 15.5 \\
\hline $\begin{array}{l}\text { (b) Energy-saving technologies in motor vehicles and in } \\
\text { traffic engineering, namely* }\end{array}$ & 421 & 18.3 \\
\hline In engines of motor vehicles & 369 & 16.0 \\
\hline $\begin{array}{l}\text { In motor vehicle bodies (e.g., through the decrease of } \\
\text { weight; the improvement of aerodynamics) }\end{array}$ & 164 & 7.1 \\
\hline In traffic management system & 138 & 6.0 \\
\hline (c) Energy-saving technologies in buildings, namely* & 1,038 & 45.0 \\
\hline In temperature isolation & 631 & 27.4 \\
\hline In lighting (incl. respective control systems) & 732 & 31.7 \\
\hline In heating (incl. respective control systems) & 717 & 31.1 \\
\hline In cooling systems & 468 & 20.3 \\
\hline In air ventilation and air conditioning & 562 & 24.4 \\
\hline $\begin{array}{l}\text { (d) Energy-saving technologies in power-generating } \\
\text { processes, namely* }\end{array}$ & 501 & 21.7 \\
\hline $\begin{array}{l}\text { Combined heat and power generation } \\
\text { based on Biomass }\end{array}$ & 25 & 1.1 \\
\hline $\begin{array}{l}\text { Combined heat and power generation } \\
\text { based on oil/gas/carbon }\end{array}$ & 83 & 3.6 \\
\hline Heat pumps & 223 & 9.7 \\
\hline Heat recuperation systems & 406 & 17.6 \\
\hline $\begin{array}{l}\text { Share of adopters with respect to all } \\
\text { technology applications }\end{array}$ & 1,231 & 53.4 \\
\hline
\end{tabular}

* Shares of firms with at least 1 technology application in the respective type of technology applications; reference: all firms. The shares for the single applications are percentages of technology adopting firms

pressure is greater, demand elasticity can be expected to be higher because of the existence of close substitutes, thus driving firms to innovative activity or rapid new technology adoption (see, e.g., Majumdar and Venkataraman 1993). In accordance to this line of reasoning, we proxied competitive pressures through the intensity of price (PRICE_COMP) and nonprice competition (NONPRICE_COMP) on the product market (as perceived by the firms themselves) and expect a positive relationship to the propensity to adopt new technology.

In order to control for epidemic effects $E_{j}$ we use two variables, one measure for interfirm effects (share of firms having adopted new technology in the industry, in which a firm operates: INTER_...), and a second one for intra-firm effects (mean number of the firms' adopted technology applications in the industry the firm operates in: INTRA_...); see Table 2 for more details regarding the construction of the variables. 
In a cross-section analysis, inter-firm epidemic effects $\mathrm{E}_{j}$ cannot be distinguished from inter-firm order and stock effects $\mathrm{SO}_{i}$. Therefore, the estimated coefficients of these two variables measure the net effects, which may be positive (dominance of positive non-market intermediated epidemic effects and market intermediated network effects) or negative (dominance of the stock and order effects) or insignificant (the two opposite effects are equally strong), although it will not be possible to say to which type of positive effects empirically found net positive effects can be traced back.

To measure (indirectly) firm-specific adoption costs $P_{i}$ we used a group of variables indicating various barriers to the adoption of energy-saving technologies that would postpone or even hinder completely the adoption of new technology because of different types of costs. We identified four groups of such barriers based on principal component factor analysis of 14 single obstacles of adoption, the importance of which has been assessed by firms on a five-point Likert scale: ${ }^{6}$ (a) lack of compatibility with current product program or current production technology (high adjustment costs due to high sunk costs) (COMPATIBILITY); (b) excessive investment expenditures, insufficient liquidity (high financing costs) (FINANCIAL); (c) information and knowledge barriers (information costs) (INFORMATIONAL); and $(\mathrm{d})$ organizational and managerial barriers (ORGANIZATIONAL). We expect such barriers to be negatively correlated with adoption.

In order to measure inducement factors $I A_{i}$, we add the following variables to the model: (a) the sales share of energy costs as an indicator of high reactivity to energy prices and/or taxes; (b) a variable indicating a firm's willingness to take environmental criteria into consideration for procurement of intermediate inputs and thus reflecting its "intrinsic" motivation; and (c) a group of variables indicating various motives that would induce the adoption of energy-saving technologies. We identified four groups of such motives based on principal component factor analysis of 11 single motives for adoption, the relevance of which has been assessed by firms on a five-point Likert scale: ${ }^{7}$ (i) (expected) increases of energy prices and/or taxes that would enhance the propensity of the adoption of energy-saving technologies; (ii) (expected) public incentives for energy efficiency and/or $\mathrm{CO}_{2}$ reduction (PUBLIC_ INCENT); (iii) (expected) public regulations and/or agreements among firms and government agencies with respect to energy efficiency (PUBLIC_REGUL); and (iv) other motives such as the (expected) increase of demand for environment-friendly products, expected energy bottlenecks or the "intrinsic" motivation for environment-friendly behavior. We expect positive effects for the four motive variables. ${ }^{8}$

\section{Data and Descriptive Analysis}

The data used in this study was collected in the course of a survey among Swiss enterprises in the year 2009 using a questionnaire specifically designed for the analysis of economic aspects of innovation and adoption activities with regards to energy-efficient technologies. Besides questions on some basic firm characteristics (sales, exports, employment, investment and employees' vocational education), it included questions on energy-saving activities as well

\footnotetext{
6 Table A.4 in the Appendix (downloadable from the journal website, or available from the authors upon request) provides more details.

7 Table A.5 in the Appendix (downloadable from the journal website, or available from the authors upon request) provides more details.

8 These variables are available for adopting firms only.
} 
as on motives and obstacles of such activities. ${ }^{9}$ The survey was based on a disproportionately (with respect to firm size) stratified random sample of firms with more than 5 employees covering all relevant industries of the manufacturing sector, the construction sector and selected service industries (resulting in a sample structure of 29 industries and, within each industry, three industry-specific firm size classes with full coverage of large firms). This is the sample also used for the Swiss Innovation Survey, a survey conducted at regular intervals by KOF Swiss Economic Institute in accordance with the recommendations for Eurostat's Community Innovation Survey (CIS).

The final data set includes 2,324 enterprises from all fields of activity and size classes. ${ }^{10}$ Stemming from a sample size of 5,809, a response rate of $40 \%$ resulted, which we deem highly satisfactory, given the complex nature and length of the questionnaire. Moreover, the composition with respect to industry and firm size of the dataset used is quite similar to that of the underlying stratified random sample. In this sense, we can assume that our final dataset is representative of the underlying sample.

\subsection{Inter-Firm Diffusion}

On the whole, $53.4 \%$ of all responding firms reported at least one of the energy-saving technology application defined in Table 3 . The most frequently reported applications were related to buildings (group (c); $45.0 \%$ of all firms). $70.5 \%$ of such applications (i.e., $31.7 \%$ of all firms) referred to lighting; heating $(69.1 \%$, i.e., $31.1 \%$ of all firms) has been an equally important domain for energy-saving. The widespread use of such technology applications can be explained by the fact that building-related energy-saving is widely applicable in all sectors of the economy.

$39.6 \%$ of all firms used energy-saving technology applications of group (a), primarily in components of process engineering (compressors, pumps, heat exchangers, etc.), electrical machines and drive systems as well as in information and communication technologies (about $62 \%$ of them in each sub-group, i.e., about $25 \%$ of all firms).

Energy-saving technology applications in transport (group (b); $18.3 \%$ of all firms) or power-generating processes (group (d); $21.7 \%$ of all firms) have been much less frequently introduced than energy-saving technologies in the groups (a) and (c). For group (d) it is obvious that only for larger firms it can be efficient to generate their own power instead of buying it. It is remarkable that power-generating technologies based on non-fossil energy sources, which also reduce $\mathrm{CO}_{2}$-emissions, are rather rare: only $5.0 \%$ of firms with applications of group (d) (i.e., $2.0 \%$ of all firms) reported the use of combined heat-and-power generation based on biomass.

The fact that many firms reported the use of energy-saving technology applications in more than one of the four technology categories considered in this study shows that a parallel use of such technology applications is a frequent firm practice that indicates a kind of complementarity of the different technology categories with respect to a total firm-wide energy-saving goal.

All these technology applications reflect energy-saving in production processes as well as in products. Process applications are presumably dominant in the service industries and

\footnotetext{
9 Versions of the questionnaire in German, French and Italian are available at http://www.kof.ethz.ch/en/ surveys/structural-surveys/other-surveys/energy-technology-2009/.

10 See Table A. 1 in the Appendix (downloadable from the journal website, or available from the authors upon request) for the structure of the data set used by industry and firm size, respectively. In addition, this Appendix contains tables for descriptive statistics of all variables used in this study, and of their respective correlation coefficients.
} 
Table 4 Intra-firm diffusion of energy-saving technologies

\begin{tabular}{|c|c|c|c|c|c|}
\hline \multirow{2}{*}{$\begin{array}{l}\text { Type of energy-saving } \\
\text { technology } \\
\text { application }\end{array}$} & \multirow{2}{*}{$\begin{array}{l}\text { Name of associated } \\
\text { dependent variables } \\
\text { (see Table } 1 \text { ) }\end{array}$} & \multicolumn{2}{|c|}{$\begin{array}{l}\text { Number and share } \\
\text { of adopters }\end{array}$} & \multicolumn{2}{|c|}{$\begin{array}{l}\text { Number and share } \\
\text { of adopters }\end{array}$} \\
\hline & & $\mathrm{N}$ & $\%$ & $\mathrm{~N}$ & $\%$ \\
\hline \multirow{2}{*}{$\begin{array}{l}\text { (a) Energy-saving } \\
\text { technologies in } \\
\text { electromechanical and } \\
\text { electronic applications }\end{array}$} & $\begin{array}{l}\text { MACHINE } \\
\text { MACHINE_N_0 } \\
\text { MACHINE_N_5 }\end{array}$ & \multicolumn{2}{|c|}{$\begin{array}{l}\text { With } 1 \text { or } 2 \text { technology } \\
\text { applications }\end{array}$} & \multicolumn{2}{|c|}{$\begin{array}{l}\text { With } 3,4 \text { or } 5 \text { technology } \\
\text { applications }\end{array}$} \\
\hline & & 507 & 22.0 & 407 & 17.6 \\
\hline \multirow[t]{2}{*}{$\begin{array}{l}\text { (b) Energy-saving } \\
\text { technologies in } \\
\text { motor vehicles and } \\
\text { in traffic } \\
\text { engineering }\end{array}$} & $\begin{array}{l}\text { TRANSPORT } \\
\text { TRANS- } \\
\text { PORT_N_0 } \\
\text { TRANS- } \\
\text { PORT_N_3 }\end{array}$ & \multicolumn{2}{|c|}{$\begin{array}{l}\text { With } 1 \text { technology } \\
\text { application }\end{array}$} & \multicolumn{2}{|c|}{$\begin{array}{l}\text { With } 2 \text { or } 3 \text { technology } \\
\text { applications }\end{array}$} \\
\hline & & 245 & 10.6 & 176 & 7.6 \\
\hline \multirow[t]{2}{*}{$\begin{array}{l}\text { (c) Energy-saving } \\
\text { technologies in } \\
\text { buildings }\end{array}$} & $\begin{array}{l}\text { BUILDING } \\
\text { BUILD- } \\
\text { ING_N_0 } \\
\text { BUILD- } \\
\text { ING_N_5 }\end{array}$ & \multicolumn{2}{|c|}{$\begin{array}{l}\text { With } 1 \text { or } 2 \text { technology } \\
\text { applications }\end{array}$} & \multicolumn{2}{|c|}{$\begin{array}{l}\text { With } 3,4 \text { or } 5 \text { technology } \\
\text { applications }\end{array}$} \\
\hline & & 440 & 19.1 & 598 & 25.9 \\
\hline \multirow[t]{2}{*}{$\begin{array}{l}\text { (d) Energy-saving } \\
\text { technologies in } \\
\text { energy-generating } \\
\text { processes }\end{array}$} & $\begin{array}{l}\text { ENERGY EN- } \\
\text { ERGY_N_0 } \\
\text { EN- } \\
\text { ERGY_N_4 }\end{array}$ & \multicolumn{2}{|c|}{$\begin{array}{l}\text { With } 1 \text { technology } \\
\text { applications }\end{array}$} & \multicolumn{2}{|c|}{$\begin{array}{l}\text { With } 2,3 \text { or } 4 \text { technology } \\
\text { applications }\end{array}$} \\
\hline & & 318 & 13.8 & 183 & 7.9 \\
\hline
\end{tabular}

Shares of firms; reference: all firms

in manufacturing industries such as food, clothing and textile, wood processing, chemicals, plastics, metals and glass, stone and clay. Both types of applications are used in the industries producing primarily capital goods (machinery, electrical machinery, electronics and instruments and vehicles).

\subsection{Intra-Firm Diffusion}

In the present study, intra-firm diffusion cannot be measured as in studies referring to a single technology (for example, IT for E-commerce) by an intensity measure (for example, sales share by E-commerce). Thus, we apply a wider concept of intra-diffusion based on the number of technology applications (belonging to one of the four groups distinguished here) used in the firm. ${ }^{11}$

$55.5 \%$ of the firms using technology applications of group (a) reported only 1 or 2 such applications, $44.5 \%$ of them 3, 4 or 5 such applications (Table 4). The shares of firms with only low intensity of application for the other groups are: $58.5 \%$ (group b); $42.0 \%$ (group c); and $63.6 \%$ for group $(\mathrm{d})$. These figures show that, with the exception of technology applications for buildings, the intra-firm extent of usage of energy-saving technologies either in production processes or in products is rather limited. A possible explanation for this could be that most firms do not have integrated strategies of energy-saving (see, e.g., Santos da Silva

11 Of course one could define other measures, e.g., the number of technology categories or total number of technology applications across all the four technology categories. In this paper we restrict the analysis to this measure, as we think it has the larger information content. 
and Amaral 2009) but invest occasionally in the one or the other application field. However, it is a common characteristic to many technologies that intra-firm diffusion is limited after their early years (see Canepa and Stoneman 2004).

\section{Estimation Method and Empirical Results}

\subsection{Inter-Firm Diffusion}

For the reasons outlined in Sect. 3.2, we estimated a multivariate probit model, i.e., a simultaneous system of four adoption equations for the four different types of technology applications, instead of four separate probits. We applied the procedure implemented in STATA, which is based on the so-called GHK-simulator for multivariate distributions. ${ }^{12}$ The results are presented in Table 5. ${ }^{13}$ We found significant positive correlations between any pair of part-adoption equations. Thus, there is considerable empirical justification for estimating a multivariate probit model.

As discussed in Sect. 3.2, the positive correlations among the various categories of technology applications can be interpreted as a hint for the existence of complementarities among these technologies. This means that the different categories of technology applications are used parallel because they refer to different domains of enterprise functions and activities. ${ }^{14}$

Firm-specific rank effects. We find to a large extent the same pattern with respect to the variables reflecting firm-specific rank effects for all four groups of energy-saving technology applications. Obviously the likelihood that at least one of the technology applications is adopted is driven by the same firm characteristics independent from the specific type of technology applications.

Not all firm characteristics included in our variable vector are equally important for technology adoption. With respect to factor endowment, the variable for gross investment per employee ${ }^{15}$ and the dummy variable for $R \& D$ show the expected positive signs and the respective coefficients are statistically significant at the $10 \%$ test level. It is not astonishing that R\&D activities are more important for electromechanical and electronic applications [group (a)] than for the other three types of technology applications. Contrary to our expectations, adopting firms do not use more human capital than non-adopting firms. The insignificant coefficients of the variable HQUAL in Table 5 indicate that, in the case of energy-saving technologies, not the percentage of employees with tertiary-level education but rather the existence of R\&D activities constitutes a crucial precondition for adopting such new technologies. ${ }^{16}$

\footnotetext{
12 The STATA procedure 'mvprobit' estimates M-equation probit models by the method of simulated maximum likelihood. The Geweke-Hajivassiliou-Keane (GHK)-simulator is applied to evaluate the M-dimensional Normal integrals in the likelihood function (for a description of the GHK-simulator see Greene 2003).

13 Table 1 shows the construction of the respective four binary variables, Table 2 contains the explanatory variables in accordance with the model specification in Sect. 3.

14 Complementarities between various advanced manufacturing technologies were also found, for example, in Colombo and Mosconi (1995), Stoneman and Toivanen (1997), and Arvanitis and Hollenstein (2001).

15 The equations in Tables 5 and 6 also contain the dummy variable INVEST/EMPL_0 as control for firms with null gross investment in 2008.

16 The possibility that multicollinearity effects due to the correlation between the variables R\&D and HQUAL $(r=0.17)$ could be responsible for the insignificant coefficient for HQUAL was examined in estimates of all four equations without the variable $R \& D$. The coefficient for $R \& D$ remained in this case statistically insignificant at the $10 \%$ test-level.
} 
Table 5 Determinants of inter-firm adoption of several types of energy-saving technologies; tetravariate probit estimates

\begin{tabular}{|c|c|c|c|c|}
\hline $\begin{array}{l}\text { Explanatory } \\
\text { variables }\end{array}$ & MACHINE & TRANSPORT & BUILDING & ENERGY \\
\hline \multicolumn{5}{|l|}{ Firm-specific rank effects } \\
\hline LOG_EMPL & $0.180(0.022)^{* * *}$ & $0.163(0.024) * * *$ & $0.247(0.023)^{* * *}$ & $0.214(0.024)^{* * *}$ \\
\hline LOG_INVEST/EMPL & $0.089(0.025)^{* * *}$ & $0.053(0.029)^{*}$ & $0.101(0.024)^{* * *}$ & $0.209(0.029)^{* * *}$ \\
\hline INVEST/EMPL_0 & $0.426(0.304)$ & $-0.066(0.397)$ & $0.531(0.294)^{*}$ & $1.632(0.381)^{* * *}$ \\
\hline HQUAL & $0.000(0.002)$ & $-0.003(0.002)$ & $-0.002(0.002)$ & $-0.002(0.002)$ \\
\hline $\mathrm{R} \& \mathrm{D}$ & $0.398(0.076)^{* * *}$ & $0.195(0.085)^{* *}$ & $0.261(0.076)^{* * *}$ & $0.304(0.082)^{* * *}$ \\
\hline EXPORT & $0.006(0.075)$ & $-0.120(0.083)$ & $0.028(0.073)$ & $0.027(0.085)$ \\
\hline FOREIGN & $0.004(0.086)$ & $-0.131(0.100)$ & $-0.188(0.085)^{* *}$ & $-0.187(0.095)^{*}$ \\
\hline \multicolumn{5}{|c|}{ Market environment specific rank effects } \\
\hline DEMAND_EXPECT & $0.056(0.037)$ & $-0.002(0.042)$ & $0.104(0.036)^{* * *}$ & $0.056(0.041)$ \\
\hline PRICE_COMP & $0.081(0.031)^{* * *}$ & $0.057(0.034)^{*}$ & $0.040(0.030)$ & $0.063(0.034)^{*}$ \\
\hline NONPRICE_COMP & $0.032(0.033)$ & $-0.027(0.037)$ & $0.048(0.032)$ & $-0.010(0.037)$ \\
\hline \multicolumn{5}{|l|}{ Barriers of adoption } \\
\hline INFORMATIONAL & $0.151(0.031)^{* * *}$ & $0.147(0.035)^{* * *}$ & $0.220(0.030)^{* * * *}$ & $0.103(0.034) * * *$ \\
\hline ORGANIZATIONAL & $0.039(0.030)$ & $0.013(0.033)$ & $0.007(0.029)$ & $-0.023(0.033)$ \\
\hline FINANCIAL & $0.215(0.031)^{* * *}$ & $0.152(0.036)^{* * *}$ & $0.277(0.031)^{* * *}$ & $0.143(0.035)^{* * *}$ \\
\hline COMPATIBILITY & $-0.246(0.030)^{* * *}$ & $-0.139(0.034)^{* * *}$ & $-0.237(0.030)^{* * *}$ & $-0.213(0.034) * * *$ \\
\hline \multicolumn{5}{|l|}{ Inducement effects } \\
\hline LOG_EXP_ENERGY & $0.030(0.029)$ & $-0.020(0.032)$ & $-0.029(0.028)$ & $0.062(0.033)^{*}$ \\
\hline EXP_ENERGY_0 & $-0.428(0.167)^{* *}$ & $-0.439(0.207)^{* *}$ & $-0.310(0.157)^{* *}$ & $-0.294(0.212)$ \\
\hline ENV_AWARE & $0.230(0.030)^{* * *}$ & $0.147(0.033)^{* * *}$ & $0.181(0.029)^{* * *}$ & $0.156(0.033)^{* * *}$ \\
\hline \multicolumn{5}{|l|}{ Epidemic effects } \\
\hline INTER_MACHINE & $2.103(0.610)^{* * * *}$ & & & \\
\hline INTRA_MACHINE & $-0.070(0.181)$ & & & \\
\hline INTER_TRANSPORT & & $3.624(0.404) * * *$ & & \\
\hline INTRA_TRANSPORT & & $0.119(0.210)$ & & \\
\hline INTER_BUILDING & & & $1.998(0.571)^{* * *}$ & \\
\hline INTRA_BUILDING & & & $0.073(0.122)$ & \\
\hline INTER_ENERGY & & & & $3.336(0.580)^{* * *}$ \\
\hline INTRA_ENERGY & & & & $-0.789(0.335)^{* *}$ \\
\hline Const. & $-4.139(0.613) * * *$ & $-3.652(0.547)^{* * *}$ & $-4.635(0.493)^{* * *}$ & $-4.550(0.492)^{* * *}$ \\
\hline No. of obs. & 2,285 & & & \\
\hline LR chi2 & 1096.7 & & & \\
\hline$p$ value & 0.000 & & & \\
\hline \multicolumn{5}{|c|}{ Estimated residual correlation coefficients } \\
\hline Rho21 & $0.578(0.031)^{* * *}$ & & & \\
\hline Rho31 & $0.725(0.020)^{* * *}$ & & & \\
\hline Rho41 & $0.533(0.031)^{* * * *}$ & & & \\
\hline Rho32 & $0.545(0.031)^{* * *}$ & & & \\
\hline Rho42 & $0.291(0.038)^{* * *}$ & & & \\
\hline Rho43 & $0.632(0.029)^{* * *}$ & & & \\
\hline
\end{tabular}

See Table 1 and 2 for the definition of the variables. Estimations include industry dummy variables (not shown here) as defined in Table 2

$* * *, * *, *$ denote statistical significance at the 1,5 and $10 \%$ test level. 
Table 6 Determinants of inter-firm adoption of several types of energy-saving technologies; separate probit estimates; marginal effects/discrete differences

\begin{tabular}{|c|c|c|c|c|}
\hline $\begin{array}{l}\text { Explanatory } \\
\text { variables }\end{array}$ & MACHINE & TRANSPORT & BUILDING & ENERGY \\
\hline \multicolumn{5}{|l|}{ Firm-specific rank effects } \\
\hline LOG_EMPL & $0.056(0.007)^{* * *}$ & $0.036(0.005)^{* * *}$ & $0.078(0.007)^{* * *}$ & $0.051(0.006)^{* * *}$ \\
\hline LOG_INVEST/EMPL & $0.029(0.008)^{* * *}$ & $0.012(0.007)^{*}$ & $0.031(0.008)^{* * *}$ & $0.048(0.007)^{* * *}$ \\
\hline INVEST/EMPL_0 & $0.136(0.098)$ & $-0.036(0.082)$ & $0.141(0.092)$ & $0.432(0.113) * * *$ \\
\hline HQUAL & $-0.000(0.001)$ & $-0.001(0.000)$ & $-0.001(0.001)$ & $-0.001(0.000)^{*}$ \\
\hline $\mathrm{R} \& \mathrm{D}$ & $0.142(0.025)^{* * *}$ & $0.044(0.021)^{* *}$ & $0.089(0.025)^{* * *}$ & $0.074(0.021)^{* * *}$ \\
\hline EXPORT & $-0.004(0.023)$ & $-0.027(0.019)$ & $0.003(0.023)$ & $0.005(0.020)$ \\
\hline FOREIGN & $0.004(0.027)$ & $-0.036(0.021)^{*}$ & $-0.065(0.026)^{* *}$ & $-0.050(0.021)^{* *}$ \\
\hline \multicolumn{5}{|c|}{ Market environment specific rank effects } \\
\hline DEMAND_EXPECT & $0.016(0.012)$ & $0.002(0.010)$ & $0.033(0.011)^{* * *}$ & $0.014(0.010)$ \\
\hline PRICE_COMP & $0.026(0.010)^{* * *}$ & $0.012(0.008)$ & $0.013(0.010)$ & $0.016(0.008)^{*}$ \\
\hline NONPRICE_COMP & $0.009(0.010)$ & $-0.004(0.009)$ & $0.013(0.010)$ & $-0.002(0.009)$ \\
\hline \multicolumn{5}{|l|}{ Barriers of adoption } \\
\hline INFORMATIONAL & $0.047(0.009)^{* * * *}$ & $0.032(0.008)^{* * * *}$ & $0.072(0.009)^{* * * *}$ & $0.021(0.008)^{* * * *}$ \\
\hline ORGANIZATIONAL & $0.012(0.009)$ & $0.003(0.008)$ & $0.004(0.009)$ & $-0.006(0.008)$ \\
\hline FINANCIAL & $0.066(0.009)^{* * *}$ & $0.031(0.008)^{* * *}$ & $0.089(0.009)^{* * *}$ & $0.032(0.008) * * *$ \\
\hline COMPATIBILITY & $-0.075(0.009) * * *$ & $-0.029(0.008)^{* * *}$ & $-0.079(0.009)^{* * *}$ & $-0.049(0.008)^{* * *}$ \\
\hline \multicolumn{5}{|l|}{ Inducement effects } \\
\hline LOG_EXP_ENERGY & $0.010(0.009)$ & $-0.003(0.007)$ & $-0.008(0.009)$ & $0.016(0.008)^{* *}$ \\
\hline EXP_EMERGY_0 & $-0.139(0.047)^{* * *}$ & $-0.080(0.034)^{* *}$ & $-0.091(0.049)^{*}$ & $-0.061(0.040)$ \\
\hline ENV_AWARE & $0.070(0.009) * * *$ & $0.035(0.008)^{* * *}$ & $0.057(0.009)^{* * *}$ & $0.037(0.008)^{* * *}$ \\
\hline \multicolumn{5}{|l|}{ Epidemic effects } \\
\hline INTER_MACHINE & $0.533(0.213)^{* *}$ & & & \\
\hline INTRA_MACHINE & $-0.030(0.066)$ & & & \\
\hline INTER_TRANSPORT & & $0.768(0.094)^{* * *}$ & & \\
\hline INTRA_TRANSPORT & & $0.032(0.051)$ & & \\
\hline INTER_BUILDING & & & $0.548(0.197)^{* * *}$ & \\
\hline INTRA_BUILDING & & & $-0.006(0.045)$ & \\
\hline INTER_ENERGY & & & & $0.759(0.142)^{* * *}$ \\
\hline INTRA_ENERGY & & & & $-0.212(0.086)^{* *}$ \\
\hline No. of obs. & 2,285 & 2,285 & 2,285 & 2,285 \\
\hline Pseudo-R2 & 0.1826 & 0.1487 & 0.2088 & 0.2152 \\
\hline LR chi2 & 560.2 & 323.3 & 656.7 & 515.0 \\
\hline$p$ value & 0.0000 & 0.0000 & 0.0000 & 0.0000 \\
\hline
\end{tabular}

See Tables 1 and 2 for the definition of the variables. Estimations include industry dummy variables (not shown here) as defined in Table 2

$* * *, * *, *$ denote statistical significance at the 1,5 and $10 \%$ test level. Marginal effects are shown except for dummy variables where discrete differences in outcomes are shown

Firm size shows the expected (non-linear) positive effect. There are some differences among the various technology types with respect to foreign-owned firms. Foreign firms seem to be less inclined than domestic firms to adopt energy-saving technologies in buildings and 
energy-generating processes. A possible explanation for this effect is that foreign firms more often than domestic firms do not use own buildings or own energy-generation processes, thus they are not responsible for this kind of investment in energy-saving technologies. ${ }^{17}$ Finally, export activities do not appear to be a specific trait of adopting firms.

Most of the studies with a similar theoretical background known to us investigate the diffusion of advanced manufacturing technologies or of information and communication technologies (ICT). For this reason we discuss in this paragraph the similarities or differences of our results with respect to these studies, in the sense of a test of the range of the validity of the underlying common theoretical approach. Most empirical studies on advanced manufacturing technologies - this is one of the fields that have been most intensively investigated in empirical research on technology diffusion-also find positive effects of firm size on inter-firm diffusion (see Karshenas and Stoneman 1995 and Canepa and Stoneman 2004 for surveys of this literature). Recently, also studies on ICT diffusion show similar positive effects (see, e.g., Hollenstein 2004 and Bertschek and Fryges 2002). The evidence for the effect of human capital intensity also shows positive effects on inter-firm diffusion: for example, Battisti et al. (2007, 2009) found a positive effect on inter-firm diffusion of ICT for both Swiss and UK firms; Arvanitis and Hollenstein (2001) reported a positive effect on inter-firm diffusion of advanced manufacturing technologies. Less clear is the evidence for in-house R\&D and/or innovative activities: these are found to be important by Battisti et al. (2007) for UK firms (but not for Swiss firms), Battisti et al. (2009) for UK firms, Hollenstein and Woerter (2008) and Arvanitis and Hollenstein (2001) for Swiss firms, Arundel and Sonntag (1999) for Canadian firms, but not by Colombo and Mosconi (1995) for Italian firms. In sum, the firm-specific rank effects in this study are broadly in accordance to existing empirical literature.

Rank effects of market environment. Competitive pressures as measured by the intensity of price competition (PRICE_COMP) are relevant for at least two technology groups, electromechanical and electronic applications (variable MACHINE) and energy-generating processes (ENERGY), also for transport applications (TRANSPORT) (in the estimates in column 2 in Table 5) but not for building applications (BUILDING). On the whole, competitive pressures seem to have some influence on the propensity to adopt energy-saving technologies, particularly for firms with substantial energy costs that use machinery intensively and/or generate their own power (electricity or heat).

Competitive pressures show positive effects on inter-firm diffusion partly in Hollenstein and Woerter (2008) (only for E-purchasing of Swiss firms), also partly in Dholakia and Kshetri (2004) for US firms and in Arvanitis and Hollenstein (2001) (only for the intensity of non-price competition for Swiss firms), but not in Karshenas and Stoneman (1993) for the UK and Colombo and Mosconi (1995) for Italy.

The third variable that refers to influences of the market environment, the indicator for expected demand DEMAND, seems to be of minor importance (except for building-related technologies).

Stock, order and epidemic effects. The variables for inter-firm diffusion at the industry level show positive and significant coefficients in all four equations. Similar effects were found also in earlier studies [see, e.g., Battisti et al. 2009; Hollenstein and Woerter 2008 (only for E-selling); Arvanitis and Hollenstein (2001); Colombo and Mosconi (1995)]. In contrast to this result, the coefficients for intra-firm diffusion on industry level ("cross-effect") are

\footnotetext{
17 We tested the hypothesis that diffusion obstacles, particularly compatibility impediments, may restrain foreign firms stronger than domestic firms. To this end, we inserted in the equation for ENERGY interaction terms of the obstacle variables with the dummy variable for foreign firms. Estimates not presented here showed no significant effect for the interaction terms.
} 
statistically insignificant at the $10 \%$ test level in three out of four equations in Table 5, but significantly negative in the equation for adoption of technology applications in power-generating processes (ENERGY). This negative effect means that more intensive use of such technologies by other firms has a downward impact on the likelihood of such technologies being adopted. Existing similar literature has yielded mixed evidence: for example, Battisti et al. (2009) found a positive effect; Hollenstein and Woerter (2008) could not find any significant effect.

In sum, inter-firm epidemic (learning) and network effects seem to outweigh negative effects of the stock and order kind leading to positive net effects that enhance the inter-firm adoption rate of energy-saving technologies. This is not the case for intra-firm epidemic (and/or eventually network effects), with the exception of the ENERGY technology applications. Thus, for the introduction of energy-saving technologies, is relevant the experience of first use of such technologies in other firms and not the intensity of own usage of these technologies (for example, the number and width of used technology applications).

Adoption costs. Adoption costs are only indirectly modeled in this study. Our model contains variables for four potential barriers that could increase adoption costs. Lack of compatibility with current product program or current production technology seems to be the main barrier for firms hindering them from adopting any kind of energy-saving technologies. The respective variable COMPATIBILITY has a significantly negative coefficient in all four equations in Table 5. Contrary to our expectations, we obtained significant but positive coefficients for the variables for financing obstacles (FINANCIAL) and for information and knowledge barriers (INFORMATIONAL) in all four estimates. These findings mean that non-adopting firms seem to anticipate these two types of obstacles less as a problem than adopting firms. This is because technology adoption involves a learning process. Technology users face problems that they assessed to be less severe before the adoption and have to be solved during the adjustment process. We conclude that information on impediments in surveys should not be interpreted as impenetrable barriers. Rather, they often reflect a problem awareness that increases with experience in technology use (see Baldwin and Lin 2002 for a similar line of argumentation based on evidence for technology adoption in Canadian firms). Finally, the fourth group of potential barriers, organizational and managerial impediments, does not seem to have an influence on the adoption rate. ${ }^{18}$

Inducement effects. The level of the sales share of energy costs is positively correlated only with the propensity to adopt energy-saving technologies in power-generating processes. Further, we obtain a positive effect for the second variable for inducement effects ENV_AWARE (reflecting "intrinsic" motivation) in all four equations in Table 5. Both results can be interpreted as hints that inducement effects are relevant for explaining the adoption rate of such technologies.

Marginal effects for the binary outcomes of this model are presented in Table 6. These are more suited for quantitative interpretations of the results. Due to technical limitations, these marginal effects are calculated on the basis of four separate probit models. ${ }^{19} \mathrm{We}$ are confident that quantitative interpretations do not suffer from this shortcoming, since by inspecting the 'raw' (as opposed to marginal effects) results of four separate probit models (available from the authors upon request) and comparing them to the multivariate probit estimates, only negligible deviations could be detected.

\footnotetext{
18 Earlier studies using also variables for adoption impediments brought out rather heterogeneous results due to the heterogeneity of the impediments that were considered; see, e.g., Hollenstein and Woerter (2008), Dholakia and Kshetri (2004), Baldwin and Lin (2002), Arvanitis and Hollenstein (2001).

19 A the time of writing of this article, there is no suitable 'margins' postestimation command available to the STATA 'mvprobit' procedure.
} 
Some quantitative interpretations of results can be made on the basis of Table 6, where marginal effects are presented. Since explanatory variables in this study are of various types (continuous vs. discrete, unbounded vs. bounded), we limit ourselves to comparing variables of the same type only. In the case of the three continuous variables LOG_EMPL (firm size), LOG_INVEST/EMPL (investment intensity) and LOG_EXP_ENERGY (energy intensity), it is evident that their relative importance is decreasing in the order they are mentioned here. The predicted semi-elasticity of the adoption share with respect to firm size varies between about 4 (transport) and 8 (buildings) percent, depending on technology class. For the variables measured on a five-point likert scale, three out of four barriers of adoption (the exception being the evidently insignificant variable "organizational barriers") plus the variable for intrinsic motivation ENV_AWARE nearly all have marginal effects lying in a range between 3 and $8 \%$. By contrast, the three variables measuring market environment specific rank effects (measured on a five-point likert scale as well) are, on average, by far less important. Finally, looking at the dummy variables, ${ }^{20}$ we find R\&D to be quantitatively the most important (plus 14 percentage points for electromechanical and electronics, for instance), followed by FOREIGN (minus 7 percentage points in the case of building technologies) and EXPORT (not significant and never above 3 percentage points).

\subsection{Intra-Firm Diffusion}

We address the issue of intra-firm diffusion by estimating a multinomial logit model for each of the four groups of energy-saving technology applications that were presented in Sect. 5 (see Table 7). Multinomial models allow for each of the four technology groups considered here to differentiate between the determinants of two different types of choice, namely (a) whether or not to adopt energy-saving technologies; and (b) whether to use them at a high degree of intensity (i.e., by adopting a combination of several applications) or not (i.e., adopting a limited number of applications only). We used a multinomial logit rather than multinomial probit estimator because the former allows testing for the "Independence from Irrelevant Alternatives“ (IIA) assumption (Hausman and McFadden 1984). We conducted Hausman tests for each of the eight coefficient vectors reported in Table 7, and none of the associated chi-quadrate statistics hinted to a violation of the IIA assumption at any conventional level of statistical significance. It is thus the appropriate method to use a multinomial logit estimator for the present analysis rather than a nested logit (which does not require the IIA assumption, but imposes additional assumptions regarding the choice by firms of technology alternatives). ${ }^{21}$

A drawback of these models is that they cannot take into account interdependencies across the four technology groups, as has been possible in the previous section by relying on the multivariate probit model. Despite this restriction, we consider the additional insights gained here as sufficiently valuable and robust. $^{22}$

${ }^{20}$ Discrete differences of the predicted outcome instead of marginal effects have been computed for dummy variables.

21 Alternatively, we also estimated ordered probit models for 3 levels (and 3, 4 or 5 levels dependent on the maximum number of single technology applications reported as adopted by a firm in one of the four categories of energy-saving technology applications). There are no notable differences between these estimates and the estimates for inter-firm adoption because the differences between adopting and non-adopting behavior dominate the results in both cases, so that the intra-firm differences are not discernible.

22 We are confident about the fact that not being able to take into account interdependencies across technology groups does not discernibly affect model estimates by referring to the results of the previous subsection: there, estimating separate probit models (on which Table 6 is based) instead of the multivariate probit (Table 5) had only negligible effects on the estimates. 


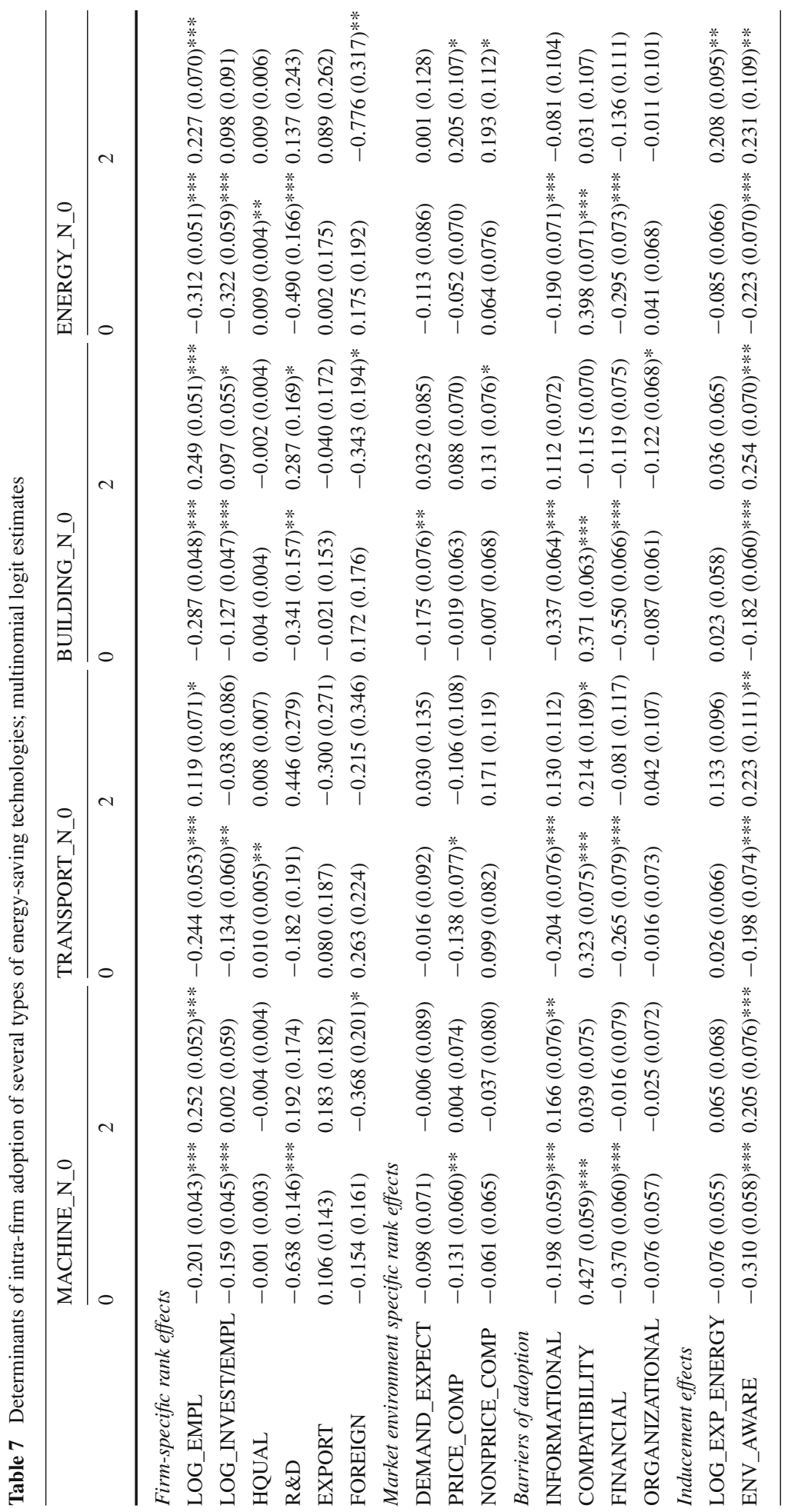




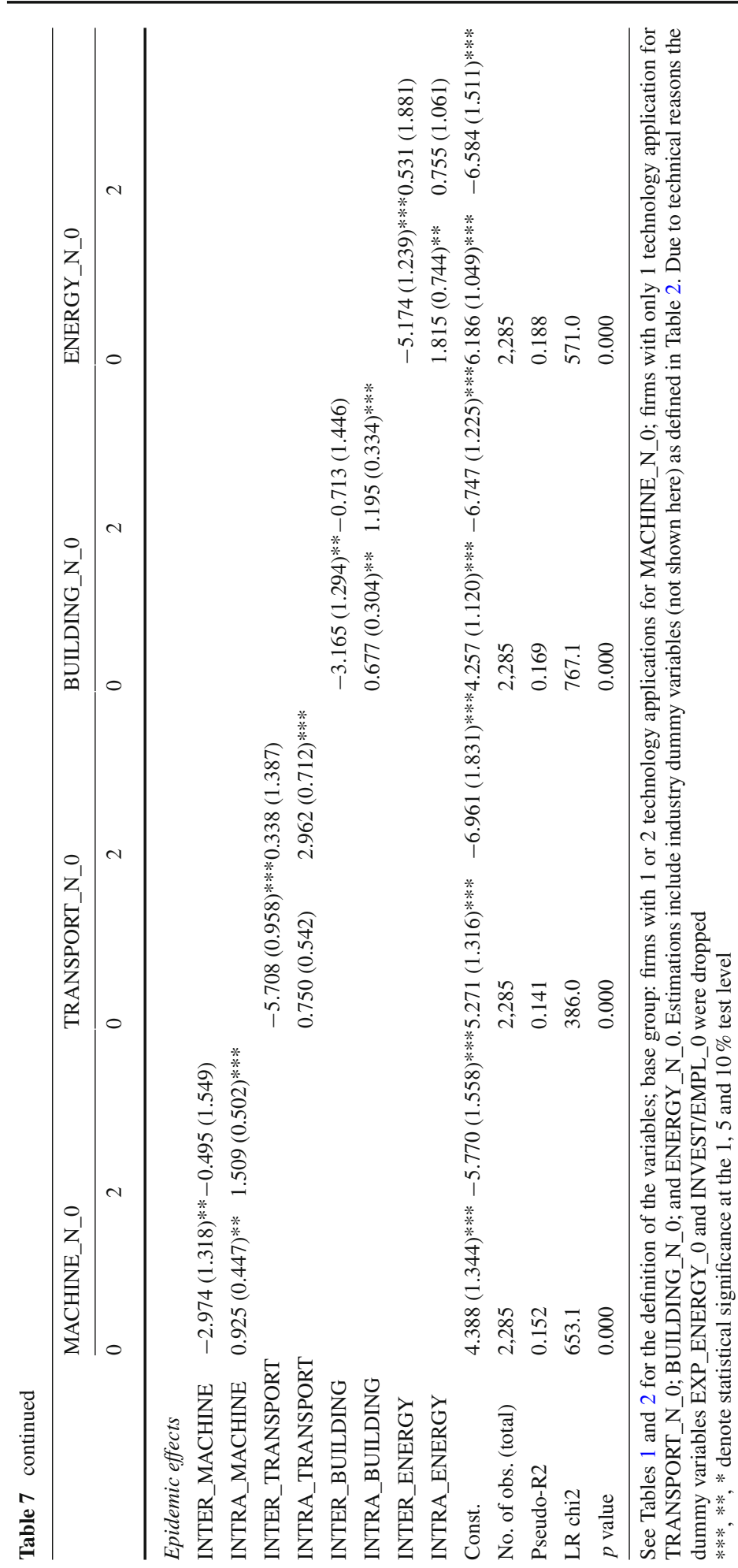


Table 1 shows the construction of the respective four dependent variables that contain three mutually exclusive groups of firms' states (non-adopting; "low-intensity" adopting; "high-intensity" adopting firms). We chose level 1 as base level, so that the estimates reflect the comparison of "low-level" adopting behavior either with non-adopting behavior or "highlevel" adopting behavior. Table 2 contains the explanatory variables in accordance with the model specification in Sect. 3. The columns 1, 3, 5 and 7 in Table 7 contain the estimates for the comparison between non-adopting and "low-level" adopting behavior. These estimates are qualitatively the same as those in the probit estimates in Table 5, with the exception of the variables for intra-firm epidemic effects in the estimates for MACHINE and BUILDING that have now rather unexpectedly positive signs, hinting to negative effects.

We concentrate here on the intra-firm effects ("high-intensity"-adopting versus "lowintensity" adopting behavior) that are found in the columns 2, 4, 6 and 8 in Table 7. There are significant differences from the pattern of relevant explanatory factors for inter-firm adoption found in Table 5. Some of the factors that were important for the inter-firm adoption rate lost their importance for explaining the extent of usage of energy-saving technologies. Factor endowment in the form of gross investment per employee and R\&D showed no effect on the rate of intra-firm adoption, with the exception of a rather weak positive effect of gross investment in the case of building-related technologies (BUILDING; column 6 in Table 7). Firm size showed a positive effect in all four equations in Table 7 also on intra-firm adoption. Foreign firms are less inclined than domestic firms to more intensive use of energy-saving technologies (with the exception of transport-related technologies). Competitive pressures remained also relevant but non-price competition appears to be more effective than price competition in the case of intra-firm adoption. It seems that more intensive usage of new technologies requires higher technological capabilities, which are available mostly to firms that are more strongly exposed to non-price competition with respect to qualitative and technological product characteristics.

The results with respect to the variables for inter-firm and intra-firm external effects are symmetrical to those for inter-firm diffusion. The intra-firm effects (direct effects) are significantly positive in three out of four types of technology applications, positive but statistically insignificant in the case of the fourth category (d) of power-generating technology applications (ENERGY). All four cross-effects (inter-firm) are insignificant. Therefore, also in the case of intra-firm adoption the direct epidemic (and/or eventually network effects) seem to outweigh stock and order effects, with the exception of power-generating technology applications. In the latter case no influence of external effects could be found.

As to adoption barriers, information and knowledge obstacles showed positive coefficients only for machinery-related technology applications. Financial and organizational barriers were of no relevance. Finally, compatibility barriers that appeared to be "proper" impediments of adoption in case of inter-firm diffusion changed the sign to positive in the equation for transport-related equation (column 4 in Table 7) indicating now a problem awareness that increases with more intensive technology use (see the discussion of such effects in Sect. 5.1).

The sales share of energy costs is positively correlated with the rate of intra-firm adoption only in the equation for ENERGY, as it was the case also in the inter-firm estimates. The second variable for inducement effects reflecting the "intrinsic" motivation for adopting environment-friendly technologies (ENV_AWARE) has again a significantly positive coefficient throughout the estimates in the columns 2, 4, 6 and 8 .

The evidence from comparable earlier studies that investigated intra-firm diffusion is mixed. In general, most studies found that the firm-specific factors that explain inter-firm adoption and intra-firm adoption are not the same. For example, firm size can be positively, 
negatively or not at all correlated with the intra-firm adoption rate, while most studies find a positive correlation of firm size and inter-firm adoption rate. Furthermore, the significance of the external effects substantially differ from study to study: For example Battisti et al. (2009) found negative effects of the inter-firm diffusion variable (on industry level) and positive effects of the intra-firm diffusion variables (on industry level) and Hollenstein and Woerter (2008) estimated significant positive coefficients only for the intra-firm variables. On the other hand, Battisti et al. (2007) found both for Switzerland and the UK positive effects of the intra-firm variable, but no effects for Switzerland and a negative effect for the UK for the inter-firm variable; the findings for Switzerland are in accordance with the results of this study. Finally, Battisti and Stoneman (2005) could not find any significant external effects on intra-firm adoption. On the whole, the empirical findings for intra-firm adoption are more heterogeneous than those for inter-firm adoption. A first possible explanation for this difference could be that intra-firm dissemination of technology is much more idiosyncratic than inter-firm diffusion, thus depending much stronger than the latter on specific characteristics such as management abilities, organization forms, etc. A further explanation could be that the potential for the more intensive use of such divergent technologies is rather limited as compared, for example, to the utilization potential of ICT technologies.

\subsection{Motives of Intra-Firm Diffusion}

In order to be able to utilize the four variables for adoption inducements that were measured only for firms that have adopted at least one technology application in any of the four categories considered in this study, we estimated a multinomial logit model for a sub-sample that contained only the firms with at least one technology application (Table 8). In such a procedure obviously the issue of potential selection bias of the estimates that are based on this sub-sample arises. A comparison of the results in Table 7 (all firms) and Table 8 (only adopting firms), particularly those for the level 2 (columns 2, 4, 6 and 8 in both tables) shows that the estimates remain quite stable when the observations of non-adopting firms are removed from the sample in the estimates in Table 8. This is a clear hint that sample selection does not make a difference in this case. We also examined the selectivity bias issue in the framework of a bivariate probit model with sample selection (Heckman approach) for the variable MACHINE. ${ }^{23}$ The selection as well as the intensity equation contained the same right-hand variables as in Tables 5, 6 and 7; the selection equation included as additional (identifying) variable the employment share of apprentices. The results (not presented here) revealed no selection bias. As a consequence, the intensity equation may be estimated as a simple probit model. The results were qualitatively the same as those obtained for the multinomial model in Table 8. This is additional evidence that the estimates in Table 8 are quite robust.

Inserting the four variables for adoption motives that reflect inducement effects in the intra-firm adoption equations did not yield substantial new insights. Increasing energy prices (and/or taxes) or public regulation (and/or public incentives to save energy - with the exception of public regulation in the case of building technology applications; column 6 in Table 8) do not seem to influence significantly the intra-firm adoption rate. However, for two categories of technology application, electromechanical and electronic applications [category (a)] and building applications [category (c)], we obtained a positive effect for the variable OTHER reflecting the following single motives: (1) current or expected demand for environment-friendly products (factor loading 0.66); (2) protection of environment

23 We applied the 'heckprob' procedure of STATA. 


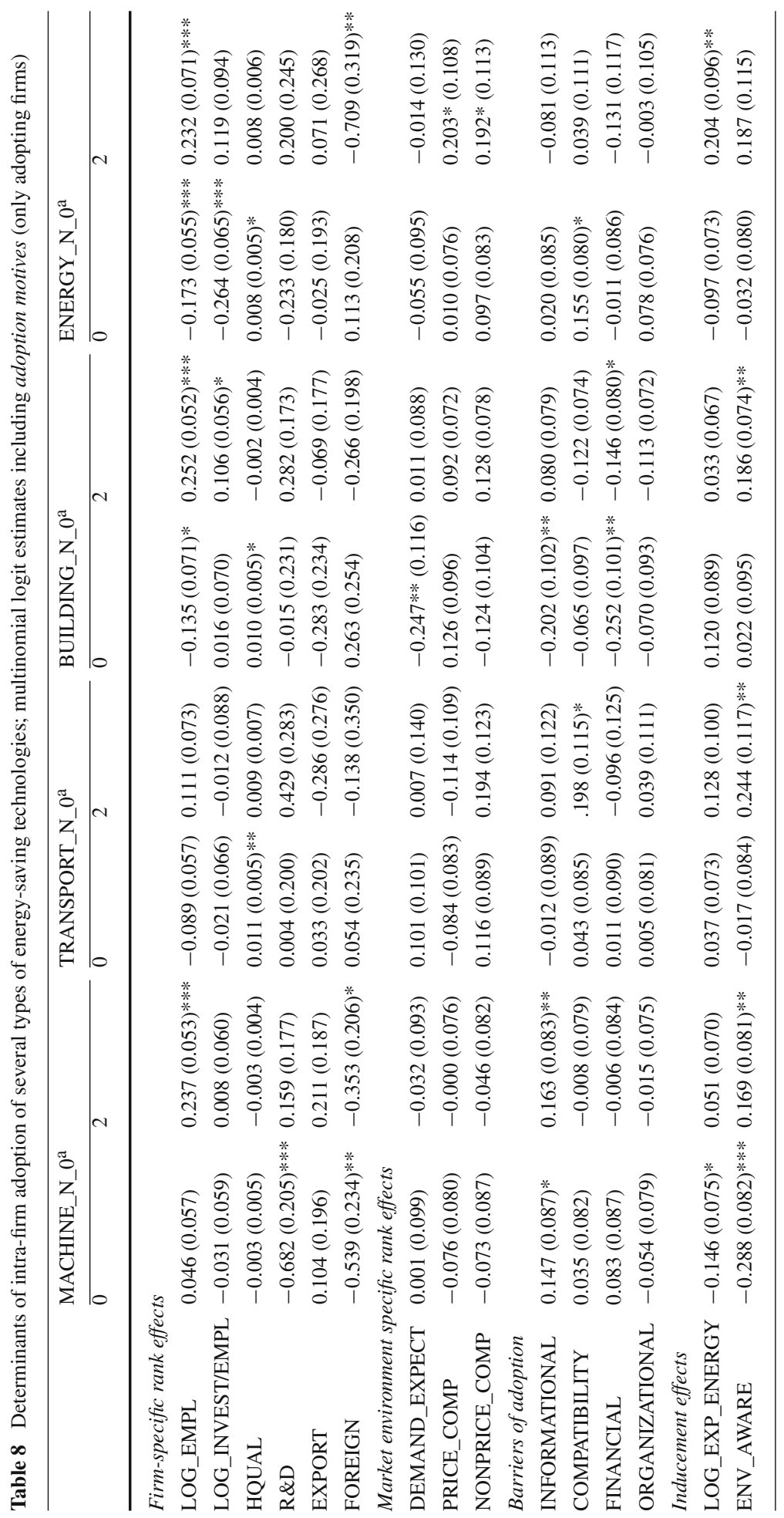




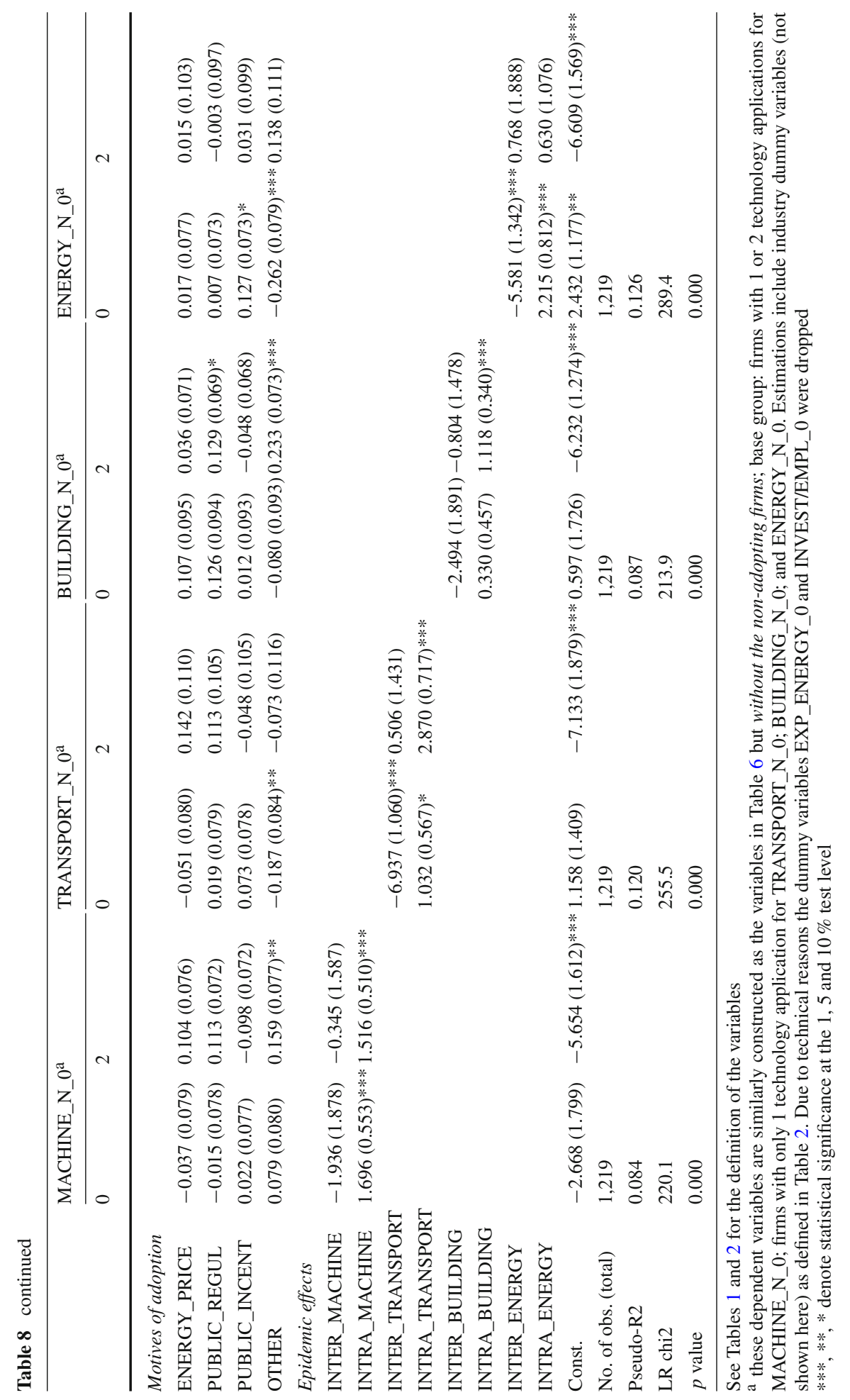


("intrinsic" motive; factor loading 0.47); and (3) uncertainty as to future energy bottlenecks (factor loading 0.21). The single motives (1) and (2) with the higher factor loadings are primarily responsible for the positive effect of the variable OTHER in the estimates for MACHINE and BUILDING. These two single motives reflect two important inducements channels: an "intrinsic" one (positive valuing of environment protection) and a second one that is market intermediated (expected demand for environment-friendly products). These findings demonstrate, in addition to the effects of the variables ENV_AWARE and LOG_EXP_ENERGY in Tables 7 and 5 (for inter-firm adoption), that there are significant inducement effects, particularly effects related to intrinsic motives for the use of energy-saving technologies.

\section{Summary and Conclusions}

We have empirically analyzed the adoption decisions of a representative sample of 2,324 Swiss firms with regards to a broad spectrum of energy-saving technologies. To this end, information on the firm-level adoption for seventeen technology applications has been grouped in four broader categories of technologies, which in turn have been confronted with an empirical model that allowed, besides the firm-specific (rank) effects, to cover the following phenomena: complementarities between technology groups, differentiating between inter-firm and intra-firm diffusion, and (net) epidemic and network versus stock and order effects. We briefly discuss key findings and present some policy implications below.

With regards to inter-firm diffusion, we find to a large extent the same pattern with respect to the variables reflecting firm-specific rank effects for all four groups of energy-saving technology applications we defined in this study. Obviously the likelihood that at least one of these technology applications is adopted is driven by similar firm characteristics, independent from the specific type of technology group.

Not all firm characteristics included in our variable vector are equally important for technology adoption. With respect to factor endowment, the variable for gross investment per employee and the dummy variable for $R \& D$ show the expected positive signs. Contrary to our expectations, adopting firms do not use more human capital than non-adopting firms. Firm size shows the expected (non-linear) positive effect. There are some differences among the various technology types with respect to foreign-owned firms. Foreign firms seem to be less inclined than domestic firms to adopt energy-saving technologies in buildings and energygenerating processes. Finally, export activities do not appear to be a specific trait of adopting firms. On the whole, competitive pressures seem to have some influence on the propensity to adopt energy-saving technologies, particularly for firms with substantial energy costs that use machinery intensively and/or generate their own power (electricity or heat).

Inter-firm epidemic (learning and, eventually, network effects) seem to outweigh negative stock and order effects leading to positive net effects that enhance the inter-firm adoption rate of energy-saving technologies. This is not the case for intra-firm epidemic and network effects; for this variable — with the exception of the ENERGY estimates - no significant effect could be found. Thus, relevant for the introduction of energy-saving technologies is the experience of first use of such technologies in other firms and not the intensity of own usage of these technologies (for example, the number and width of used technology applications).

Lack of compatibility with current product program or current production technology seems to be the main barrier for firms that hinder them from adopting any kind of energysaving technologies. Contrary to our expectations, we obtained significant but positive coefficients for the variables for financing obstacles and for information and knowledge barriers also in all four estimates. We conclude that information on impediments in surveys should 
not be interpreted as impenetrable barriers. Rather, they often reflect a problem awareness that increases with experience in technology use.

Turning to intra-firm diffusion, we find significant differences in the pattern of relevant explanatory factors as compared to inter-firm adoption. Some of the firm-specific factors (rank effects) that are important for the inter-firm adoption rate lose their importance for explaining the extent of usage of energy-saving technologies. Factor endowment in the form of gross investment per employee and R\&D shows practically no effect on the rate of intrafirm adoption. For firm size is found a positive effect in three out of four equations for intra-firm adoption. Foreign firms are less inclined than domestic firms to more intensive use of energy-saving technologies (with the exception of transport-related technologies). Competitive pressures are still relevant but non-price competition appears to be more effective than price competition in the case of intra-firm adoption. The results with respect to the variables for the inter-firm and intra-firm external effects are symmetrical to those for inter-firm diffusion. The intra-diffusion effects (direct effects) are significantly positive in three out of four types of technology applications, positive but statistically insignificant in the case of the fourth category (d) of power-generating technology applications. All four crosseffects (inter-diffusion) are insignificant. As to adoption costs, information and knowledge obstacles show positive coefficients for machinery-related and building-related technology applications. Financial and organizational barriers are of no relevance. Finally, compatibility barriers that appear to be "proper" impediments of adoption in case of inter-firm diffusion changed the sign to positive in the equation for transport-related equation.

Further, positive inducement effects, particularly effects related to intrinsic motivation for using energy-saving technologies, could be found for both inter-firm and intra-firm technology adoption.

In sum, the first use of an energy-saving technology is determined primarily by the factor endowment ( $\& \& D$, capital intensity, which mostly correlates positively with firm size), compatibility with existing technologies, inducement effects and external experience effects. This last finding is a remarkable result that points to the relevance of the industrial environment context for the diffusion of energy-saving technologies. Demand and competition conditions and-rather unexpectedly_energy intensity are of minor, if any, relevance. The extent of technology use depends less on firm-specific characteristics such as R\&D and capital intensity, but external experience effects and inducements effects that can be traced back to intrinsic motivation remain also in this case effective.

Finally, we want to make some remarks on possible implications for economic policy. The importance of rank effect indicates that the patterns of firm diffusion reflect the different strengths of firms with different characteristics. Thus, it is difficult to conceive a policy that fits to all firms. The heterogeneity of firms (for example, with respect to firm size or the existence of $\mathrm{R} \& \mathrm{D}$ activities) has to be taken into consideration when a promotion policy is formulated. In order to be effective, policy should be specific not only to technology types as is often done, but also to firm categories. Intrinsic motivation based on positive valuing of environmental protection is an important determinant of adoption that can be enhanced by policy measures. Finally, although our results are based only on a single cross-section of firms and are not definite, they yield some evidence that there exist positive technological (and eventually network externalities) in the diffusion of energy-saving technologies that would enhance the propensity as well as the extent of usage of such technologies. ${ }^{24}$

\footnotetext{
24 In the presence of such externalities firms with a "first adopter" profile may be discouraged to invest in the technology or invest sub-optimally if they are not able to appropriate all revenues from their investment. We cannot exclude this case, but in our estimates (with just one exception) potential negative stock and order effects are outweighed by positive learning effects.
} 
For power-generating technology applications (category d) we could not find such externalities with respect to intra-firm adoption. In this case, public promotion of information platforms and the like that provide firms with information about the technical possibilities of energy-saving strategies in the framework of firm-specific integrated energy-saving programs can be useful.

Acknowledgments The comments and suggestions of the participants of the 37th EARIE Conference, Istanbul, Turkey, September 4, 2010 and two anonymous referees of this journal are gratefully acknowledged.

\section{References}

Arundel A, Sonntag V (1999) Patterns of advanced manufacturing technology use in canadian manufacturing. 1998 AMT results final report, MERIT

Arvanitis S, Hollenstein H (2001) The determinants of the adoption of advanced manufacturing technology. Econ Innov New Technol 10(5):377-414

Baldwin J, Lin Z (2002) Impediments to advanced technology adoption for Canadian manufacturers. Res Policy 31:1-18

Battisti G (2000) The Intra-firm diffusion of new technologies. PhD thesis, Warwick University

Battisti G (2008) Innovations and the economics of new technology spreading within and across users: gaps and way forward. J Clean Prod 16(1):22-31

Battisti G, Canepa A, Stoneman P (2009) E-Business usage across and within firms in the UK: profitability, externalities and policy. Res Policy 38:133-143

Battisti G, Hollenstein H, Stoneman P, Woerter M (2007) Inter- and intra-firm diffusion of ICT in the United Kingdom (UK) and Switzerland (CH); an internationally comparative study based on firm-level data. Econ Innov New Technol 16(8):669-687

Battisti G, Stoneman P(2005) The intra-firm diffusion of new process technologies. Int J Ind Organ 23:1-22

Bertschek I, Fryges H (2002) The adoption of business-to business E-commerce: empirical evidence for german companies. ZEW discussion paper no 02-05, Mannheim

Binswanger HP (1974) A microeconomic approach to induced innovation. Econ J 84(336):940-958

Cadot O, Gonseth C, Thalmann P (2009) The effect of energy efficiency enhancement on innovation and competitiveness. Studie im Auftrag des Energie Trialog Schweiz und des Bundesamtes für Energie, Swiss Federal Office of Energy, Bern

Canepa A, Stoneman P (2004) Comparative international diffusion: patterns, determinants and policies. Econ Innov New Technol 13:279-298

Colombo MG, Mosconi R (1995) Complementarity and cumulative learning effects in the early diffusion of multiple technologies. J Ind Econ 43:13-48

Davies S (1979) The diffusion of process innovations. Cambridge University Press, Cambridge

De Groot HLF, Verhoef ET, Nijkamp P (2001) Energy-saving by firms: decision-making, barriers and policies. Energy Econ 23:717-740

DeCanio SJ (1993) Barriers within firms to energy-efficient investments. Energy Policy 21:906-914

DeCanio SJ (1998) The efficiency paradox: bureaucratic and organizational barriers to profitable energysaving investments. Energy Policy 5:441-454

Dholakia RR, Kshetri NN (2004) Factors impacting the adoption of internet among SMEs. Small Bus Econ 23:311-322

Fudenberg D, Tirole J (1985) Pre-emption and rent equalization in the adoption of new technology. Rev Econ Stud 52:383-401

Fuentelsaz L, Gomez J, Polo Y (2003) Intra-firm diffusion of new technologies: an empirical application. Res Policy 32:533-551

Geroski P (2000) Models of technology diffusion. Res Policy 29:603-625

Gillissen M, Opschoor H (1995) Energy conservation and investment behaviour of firms. In: Zwerver S, van Rompaey R, Kok M, Berk M (eds) Studies in environmental science. Elsevier, Amsterdam pp 1075-1080

Greene WH (2003) Econometric analysis. Prentice-Hall, New York

Hausman J, McFadden D (1984) A specification test for the multinomial logit model. Econometrica 52: 1219-1240 
Hollenstein $H$ (2004) The determinants of the adoption of information and communication technologies (ICT) - an empirical analysis based on firm-level data for the Swiss business sector. Struct Change Econ Dyn 15:315-342

Hollenstein H, Woerter M (2008) Inter- and intra-firm diffusion of technology: the example of E-commercean analysis based on Swiss firm-level data. Res Policy 37:545-564

IEA International Energy Agency (2008) Energy technology perspectives-scenarios and strategies to 2050. Paris

Ireland N, Stoneman P (1986) Technological diffusion expectations and welfare. Oxford Econ Pap 38(2): 283-304

Jacobs J, Kuper GH, van Soest DP (2009) On the effect of high energy prices on investment. Appl Econ 41: 3483-3490

Jaffe AB, Stavins N (1994) The energy-efficiency gap—what does it mean? Energy Policy 22(10):804-810

Kamien M, Schwartz N (1970) Market structure elasticity of demand and incentive to invent J Law Econ 13(1):241-252

Karshenas M, Stoneman PL (1993) Rank, stock, order, and epidemic effects in the diffusion of new process technologies: an empirical model Rand J Econ 24(4):503-528

Karshenas M, Stoneman PL (1995) Technological diffusion. In: Stoneman P (ed) Handbook of the economics of innovation and technological change. Blackwell, Oxford pp 265-297

Linn J (2008) Energy prices and the adoption of energy-saving technology Econ J 118:1986-2012

Majumdar SK, Venkataraman S (1993) New technology adoption in US telecommunications: the role of competitive pressures and firm-level inducements Res Policy 22(5-6):521-536

Montalvo C (2008) General wisdom concerning the factors affecting the adoption of cleaner technologies: a survey 1990-2007 J Clean Prod 16(1):7-13

Pizer WA, Harrington W, Kopp RJ, Morgenstern RD, Shih JS (2002) Technology adoption and aggregate energy efficiency. Resources for the future. Discussion paper 02-52, Washington DC

Popp D, Newell, RG Jaffe AD (2009) Energy, the environment, and technological change. NBER working paper 14832, Cambridge, MA

Reddy S, Painuly JP (2004) Diffusion of renewable energy technologies—barriers and stakeholders' perspectives Renew Energy 29:1431-1447

Reinganum JF (1981) Market structure and the diffusion of new technology Bell J Econ 12(2):618-624

Santos da Silva PR, Amaral FG (2009) An integrated methodology for environmental impacts and costs evaluation in industrial processes J Clean Prod 17:1339-1350

Sardianou E (2008) Barriers to industrial energy efficiency investment in Greece J Clean Prod 16:1416-1423

Sarkar J (1998) Technological diffusion: alternative theories and historical evidence J Econ Surv 12(2): $131-176$

Stoneman P, Toivanen O (1997) The diffusion of multiple technologies: an empirical study Econ Innov New Technol 5:1-17

Velthuijsen JW (1993) Incentives for investment in energy efficiency: an econometric evaluation and policy implications Environ Resour Econ 3:153-169 